\title{
Scorpionism in Brazil: exponential growth of accidents and deaths from scorpion stings
}

\author{
Pasesa Pascuala Quispe Torrez ${ }^{[1]}$, Flávio Santos Dourado ${ }^{[2]}$, Rogério Bertani ${ }^{[3]}$, \\ Palmira Cupo ${ }^{[4]}$ and Francisco Oscar de Siqueira França ${ }^{[1],[5]}$
}

\author{
[1]. Núcleo de Medicina Tropical, Departamento de Doenças Infecciosas e Parasitárias, Faculdade de Medicina, \\ Universidade de São Paulo, São Paulo, SP, Brasil. \\ [2]. Coordenação-Geral de Doenças Transmissíveis, Ministério da Saúde, Brasília, DF, Brasil. \\ [3]. Laboratório Especial de Ecologia e Evolução, Instituto Butantan, São Paulo, SP, Brasil.
}

[4]. Departamento de Puericultura e Pediatria, Faculdade de Medicina de Ribeirão Preto, Universidade de São Paulo, Ribeirão Preto, São Paulo, Brasil. [5]. Laboratório de Imunologia, Departamento de Doenças Infecciosas e Parasitárias, Faculdade de Medicina, Universidade de São Paulo, São Paulo, SP, Brasil.

\section{Dear Editor:}

Scorpionism is a neglected public health problem in Brazil, which is growing in importance owing to an increasing number of envenomations and deaths, mainly in urban centers. According to the country's public health system, the number of confirmed scorpion sting deaths has risen in the past eleven years, from 61 in 2007 to 90 in 2017, with cases of scorpion stings rising from 37,370 to 124,982 in this period. In the last 5 years (2013 to 2017) about $83 \%$ of deaths occurred within 48 hours of being stung ${ }^{1}$.

The fatality rate in victims under the age of 10 and over 75 years is $0.32 \%$ and $0.13 \%$, respectively, whereas it is usually less than $0.09 \%$ in the remaining age groups. However, in those aged between 1 and 5 years the fatality rate is $0.40 \%{ }^{1}$.

In Brazil, there are about 160 species of scorpions, but stings of medical importance are caused by the genus Tityus, which has, among other characteristics, the presence of a subaculear tubercle under the sting. Of these, four Tityus species (T. serrulatus, T. bahiensis, T. stigmurus, and T. obscurus) are of medical concern, the most important being the yellow scorpion, Tityus serrulatus ${ }^{2}$.

Corresponding author: Pasesa Pascuala Quispe Torrez.

e-mail: pasesa2@hotmail.com

Orcid: 0000-0002-2839-8466

Received 11 November 2018

Accepted 21 March 2019
The accelerated urbanization observed in Brazil in the last decades, without the adequate creation of basic infrastructure (such as water, light, sewage treatment, and regular collection of garbage), has provided conditions for the proliferation of opportunistic and invasive scorpions, such as T. serrulatus and T. stigmurus. These two species are parthenogenetic, which means the female can breed without being fertilized by males. Both are adapted to profoundly modified environments, which is the case with several cities of Brazil where the human population increased rapidly, and show great flexibility in adapting to human dwellings. This situation is characteristic of certain regions of Brazil, Mexico, and North Africa ${ }^{3,4,5}$.

The sting of Tityus serrulatus is responsible for most of the severe cases and deaths ${ }^{6,7}$. Its origin is not certain, but older records indicate towards the Brazilian state of Minas Gerais. However, today it can be found in 19 of the 27 Brazilian states.

Species identification is important, whether through capture or photography, particularly if it is one of the four Tityus species of major medical interest. In the Amazon region, Tityus obscurus requires highlighting because this species may cause acute cerebellar dysfunction ${ }^{6,7,8}$.

The severity of systemic effects caused by Tityus species depends upon the venom composition and clinical condition of the patient. In general, children under twelve and, less frequently, the elderly with comorbidities are more seriously affected. Most deaths have occurred in these age groups ${ }^{1,6,7}$.

The time between a sting and the patient's arrival at hospital/adequate treatment is very important in determining 
the prognosis ${ }^{6,9}$. Classification of the severity of scorpionism is essentially clinical. About $87 \%$ of scorpionism cases are classified as mild and characterized by local manifestations: pain, erythema, paresthesia, and sweating ${ }^{6,9}$. Treatment in these cases is restricted to the control of local pain. Occasionally, because of the pain, there may be occurrences of nausea, agitation, and mild tachycardia, which will disappear after local treatment without the need for antivenom ${ }^{6}$. But even in these cases, the patient needs to be kept under observation for at least 6 hours to detect any possible worsening of symptoms. In this situation, hospitalization for clinical management is recommended ${ }^{6,10}$.

Patients with severe manifestations can experience innumerable episodes of vomiting, profuse sweating, tachypnea, increased blood pressure, tachycardia or bradycardia, and may manifest symptoms compatible with acute congestive heart failure due to increased vascular resistance and acute lung edema ${ }^{6,9,10}$. The identification and treatment of clinical complications, early intubation in cases of acute respiratory insufficiency whenever necessary, and administration of the specific antivenom should be commenced as soon as possible. This considerably improves patient prognosis, especially in children ${ }^{6,9,10}$.

In recent years, there has been an exponential increase in the number of cases and a significant increase in the number of deaths, reaching 90 in 2017 (Figure 1) ${ }^{1}$.

Although the number of envenomations has increased in all regions of the country, deaths mainly occur in the original geographical distribution regions of $T$. serrulatus and $T$. stigmurus, which is the Southeast and Northeast, respectively. Nowadays it is likely that most deaths in the Northeast, mainly in the state of Bahia, are caused by these two species (T. stigmurus and $T$. serrulatus) $)^{3,4,5,6}$.

In relation to the number of envenomations, it was observed that in the regions where Tityus serrulatus does not or rarely occurs (North, Central-West, and South) there was a $49.5 \%$ increase in the number of cases between 2013 and $2017^{1}$. In the regions where Tityus serrulatus has a noticeable presence (Southeast and Northeast), the increase was slightly higher (57.7\%). However, the overall number of deaths in these two regions has increased, 61 of the 73 deaths $(83.6 \%)$ in the country reported during 2013 and 73 of the 90 deaths (81.1\%) reported during $2017^{1}$.

Some states deserve greater attention: in Bahia 27 deaths occurred in 2013 and 15 in 2017, in Minas Gerais deaths increased from 11 to 25, and in São Paulo there was an increase from 5 to $11^{1}$. As the native brown scorpion Tityus bahiensis is being replaced in the state of São Paulo by T. serrulatus, the exceptional increase in the number of deaths can be attributed to this last species ${ }^{3}$.

This conclusion is very likely because there is a clear overlap between the increase in the number of cases and deaths in the areas where $T$. serrulatus and $T$. stigmurus previously predominated and in urban areas where the dispersion of both has been observed more recently ${ }^{5}$.

There is a clear concern about the decrease in the production of antivenom, and subsequent decrease in the number of health

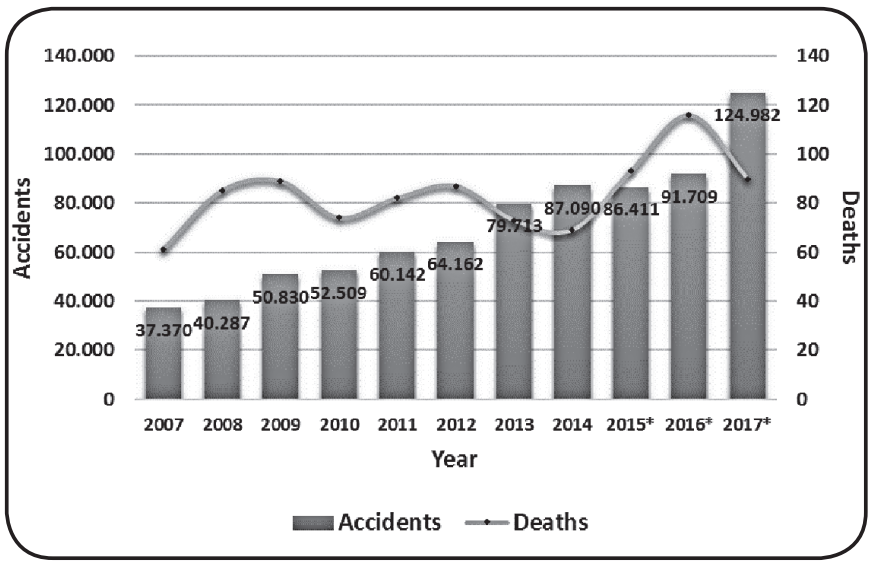

FIGURE 1: Number of envenomations and deaths caused by scorpionism, reported to SINAN (Brazil), from 2007 to 2017. The columns represent the number of envenomations reported per year. The continuous line represents the number of deaths reported per year. * Updated in December 2018.

units that have the antivenom, in Brazil during recent years. This underlines the importance of recognizing the severity of envenomation as soon as possible and transferring patients to a referral service with antivenom ${ }^{1,6}$.

The Brazilian Association of Information Centers and Toxicological Assistance (ABRACIT) consists of public institutions and provides countrywide free support by the telephone or internet on envenoming management, the nearest Reference Health Unit with antivenom, and the cities where the antivenom can be found in each state ${ }^{1,11}$.

Measures for the control and management of scorpions are based on scorpion removal/collection and modifying environmental conditions to become an unfavorable environment for the proliferation of these arachnids. This includes the active capture of scorpions where accidents are most frequent, indicated, for example, by geoprocessing or spontaneous population demand ${ }^{12}$. These measures can reduce the number of accidents and, consequently, the morbidity and mortality levels ${ }^{2}$.

Additionally, it is necessary to better understand and act against the well-known factors that are influencing the widening geographical distribution and establishment of new populations of scorpions in urban areas.

The education of health professionals and undergraduate students on the main management aspects for this neglected tropical disease is a measure that can contribute to the improvement of the control of this increasingly important public health problem.

Conflict of Interest: The authors declare that there is no conflict of interest.

\section{REFERENCES}

1. Ministério da Saúde (MS). Secretaria de Vigilância em Saúde (SVS). Sistema de Informação de Agravos de Notificação (SINAN). Saúde de A a Z. Acidentes-por-animais-peconhentos. Brasília: MS; 2018. 
Accessed June 28, 2018. Available at: http://portalms.saude.gov.br/ saude-de-a-z/acidentes-por-animais-peconhentos

2. Ministério da Saúde (MS). Secretaria de Vigilância em Saúde (SVS). Manual de Controle de Escorpiões. Brasília: MS; 2009. 74p.

3. von Eickstedt VRD, Ribeiro LA, Candido DM, Albuquerque MJ, Jorge MT. Evolution of scorpionism by Tityus bahiensis (Perty) and Tityus serrulatus Lutz and Mello and geographical distribution of the two species in the State of São Paulo - Brazil. J Venom Anim Toxins. 1996;2(2): 92-105.

4. Lourenço WR, Cloudsley-Thompson JL., Cuellar O, Von Eickstedt VRD, Barraviera B, Knox MB. The evolution of scorpionism in Brazil in recent years. J Venom Anim Toxins. 1996;2(2):121-34.

5. Bertani R, Bonini RK, Toda MM, Isa LS, Alvarez Figueiredo JV, dos Santos MR, et al. Alien scorpions in the Municipality of São Paulo, Brazil - evidence of successful establishment of Tityus stigmurus (Thorell, 1876) and first records of Broteochactas parvulus (Pocock, 1897) and Jaguajir rochae (Borelli, 1910). BioInvasions Records. 2018;7 (1): 89-94.

6. Cupo P. Clinical update on scorpion envenoming. Rev Soc Bras Med Trop. 2015;48(6):642-9.
7. Reckziegel GC, Pinto Jr VL. Scorpionism in Brazil in the years 2000 to 2012. J Venom Anim Toxins Incl Trop Dis. 2014;20:46.

8. Torrez PPQ, Quiroga MMM, Abati PAM, Mascheretti M, Costa WS, Campos L, et al. Acute cerebellar dysfunction with neuromuscular manifestations after scorpionism presumably caused by Tityus obscurus in Santarém, Pará/Brazil. Toxicon. 2015;96(1):68-73.

9. Ministério da Saúde (MS). Fundação Nacional de Saúde (FUNASA). Manual de Diagnóstico e Tratamento de Acidentes por Animais Peçonhentos. $2^{\mathrm{a}}$ edição. Brasília: MS; 2001. 112p.

10. Amaral CF, de Rezende NA, Freire-Maia L. Acute pulmonary edema after Tityus serrulatus scorpion sting in children. Am J Cardiol. 1993;71(2):242-5.

11. Associação Brasileira de Centros de Informação e Assistência Toxicológica (ABRACIT). Centros de Informação e Assistência Toxicológica (CIAT). Informações sobre os Centros de Informação e Assistência Toxicológica do Brasil. Florianópolis: CIAT/ ABRACIT. 2018. Available at: http://abracit.org.br/wp/centros/

12. Almeida TS, Fook SM, França FO, Monteiro TM, Silva EL, Gomes LC, Farias AM. Spatial distribution of scorpions according to the socioeconomic conditions in Campina Grande, State of Paraíba, Brazil. Rev Soc Bras Med Trop. 2016;49(4):477-85. 